\title{
COMPARISON OF SHORT-TERM ANALGESIC EFFECTS OF EXTRACORPOREAL SHOCK WAVE THERAPY (ESWT) AND CONSERVATIVE TREATMENT (CT) IN MEN WITH CHRONIC HEEL SPUR (HS)
}

\author{
P. Lizis \\ HOLY CROSS COLLEGE, KIELCE, POLAND
}

\begin{abstract}
Background. The surgical removal of heel spur (HS) provokes many controversial opinions, but clinical studies show the risk of complication after operation. An alternative to the surgical removal of HS is Extracorporeal Shock Wave Therapy (ESWT), because it is non-invasive method.

Objective. The aim of the study is to compare the short-term analgesic effects of ESWT and conservative treatment (CT) in males with chronic HS.

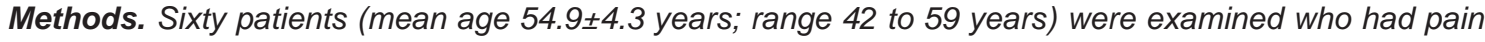
associated with HS. In the shockwave group (group 1) patients received 1000-2000 impulses of shocks to the affected heel in a single session. The patients in this group took a series of 5 ESWT in 1 week intervals. Patients in the control group (group 2) at the same time received CT consisting of nonsteroidal anti-inflammatory drugs (NSAIDs), orthotics and a local cortisone injection. The basic method of research was to evaluate pain according to Visual Analogue Scale (VAS) 0-10. The patients of the two groups were tested before the treatment, after the last treatment and 3 months and 6 months after the treatment.

Results. A significant decrease of VAS $(p=0.000)$ was seen in the shockwave group. In the control group no significant decrease of VAS was seen.

Conclusions. ESWT reduces pain more effectively than CT in men with chronic HS.
\end{abstract}

KEY WORDS: extracorporeal shock wave therapy, conservative treatment, visual analogue scale, heel spur, pain.

\section{Introduction}

Chronic inflammation of the plantar fascia, in the place of its connection to calcaneal tuberosity, can be a major cause of pain in the adult population. Due to a visible X-ray imaging calcification - bone spurs near the heel - the condition is commonly called "heel spur" (HS). Among other causes of the condition, there are: an inflammation of the Achilles tendon associated with inflammation of the Achilles tendon bursitis, inflammation of adipose tissue beneath calcaneal tuberosity by repeated micro damages that cause degeneration of the tissue, fatigue fractures of the calcaneal tuberosity, neuropathy caused by pressure on the plantar branch of the tibial nerve by an overgrown plantar aponeurosis. Risk factors also include excessive body weight, running and jumping, work that entails standing or lifting heavy objects, flat feet, rheumatic changes [15]. Originally, the condition may be asymptomaticpain rarely occurs in the early stages of the condition.

Address for correspondence: Pawel Lizis, PhD, Holy Cross College, Department of Physiotherapy, 51, Mielczarskiego Str., 25-709 Kielce, Poland

Tel.: +48413623018; Fax: +48413327451;

E-mail: pawel_lizis@poczta.onet.pl
Most patients come to the doctor in a fairly advanced stage of the condition, complaining on severe pain in the heel that escalates after they walk on hard ground or carry heavy objects and that usually disappear after they rest.

The treatment of $\mathrm{HS}$ and plantar fascia provokes many controversial opinions, many authors point to the need for surgical removal of calcaneal bursitis and resection of HS, but clinical studies show the risk of complication after operation [6-12]. An alternative to the surgical treatment of $\mathrm{HS}$ is $\mathrm{CT}$ that involves the use of physiotherapy treatments, such as ionophoresis, laser, ultrasound, and recently more and more often ESWT is used [13-16].

ESWT is a very effective method which effectiveness is comparable to surgery. The most important is the fact that it is a completely non-invasive method. It has not yet been fully explained how it works exactly, but it probably involves micro destructions - the application of ESWT causes micro breaks in avascular or poorly-vascularized tissue thus stimulating appropriate revascularization and stem cell growth. Patients may continue to work or train the next day. Given the significant reduction of activity limitations and short duration of the treatment, 
ESWT is not only comparable to surgical treatment, but, in general, it is also less expensive than a few months of CT [17-18].

The aim of the study was to compare the shortterm analgesic effects of ESWT and CT in males with chronic HS.

\section{Methods}

Continuous research was carried out in the period from January 2010 to July 2012, and involved sixty patients (middle age $54.9 \pm 4.3$ years; range from 42 to 59 years) who had pain associated with HS. The average BMI was $24.29 \pm 0.78$. None of the men was obese. The study was conducted in Busko-Zdroj Spa. The patients had unilateral pain. The average duration of pain was $15.2 \pm 5.3$ months. Inclusion criteria were pain over the X-ray examined HS, unsuccessful CT (iontophoresis, cryotherapy, laser therapy, ultrasound and phonophoresis) during the six months before referral to Spa in Busko-Zdroj. Exclusion criteria were arthritis (rheumatoid arthritis, spondarthritis, crystal induced arthropathies) diabetes mellitus, neurological abnormalities, age under 18 years, infectious or tumorous diseases, skin ulcerations, and bursitis. All patients were informed about the principles of the treatment, and they signed a written permission for treatment and participation in the study.

In the shockwave group (group 1) patients received-during the first treatment 1000 impulses, 1500 impulses in the second, and 2000 impulses in the third, fourth and fifth treatment (the pressure of $2.5 \mathrm{bar}$, the frequency of $8 \mathrm{~Hz}$, the energy density of $0.4 \mathrm{~mJ} / \mathrm{mm}^{2}$ ). The patients in the shockwave group took a series of 5 ESWT in 1 week intervals. Apparatus BTL-5000 SWT was used for the treatment. The active engagement between the head of the apparatus with a diameter of $15 \mathrm{~mm}$ and skin was gel used in ultrasound scan. The procedure was performed in the area of most intense pain calcaneal tuberosity. Treatment time did not exceed 10 minutes. Patients in the control group (group 2) at the same time received CT consisting of NSAIDs, orthotics and a local cortisone injection with $0.5 \mathrm{~mL}$ of betamethasone $(7 \mathrm{mg} / \mathrm{mL})$.

The basic method of research was to evaluate pain according to VAS, where 0 - no pain; $10-$ severe (maximum) pain at rest, after walking on awakening, and after normal daily activity. The patients of two groups were tested before the treatment, at the end of the last treatment. The patients were also examined for 3 months and 6 months after the end of treatment. The results observed were classified as excellent improvement (a VAS reduction of over $50 \%$ ), good improvement (a VAS reduction of over $30 \%$ to $50 \%$ ), slight improvement (a VAS reduction of over $15 \%$ to $30 \%$ ).
In order to evaluate the early results of the treatment, the obtained data was subjected to statistical analysis. The statistical distributions of the analyzed characteristics were examined by the use of Kolmogorov-Smirnov's test. It was shown that the tested variables had normal distribution. Basic descriptive statistics was used for the analysis. The mean arithmetic $(\Delta \mathrm{x})$ and standard deviation (SD) of the studied traits of men in both groups were calculated. In order to evaluate the statistical significance of differences in the intensity of pain before the treatment, after the last treatment and 3 and 6 months later, while at rest, while walking on awakening, and after normal daily activity, one-way analysis of variance (ANOVA) was used in both studied groups. The value of the function F Snedecor was observed in various combinations. The statistical significance of differences in the intensity of pain was assessed at the 0.05 level. Calculations were performed at the Department of Computer Science at Holy Cross University in Kielce with the use of MedCalc software - version 11.4.3.0, licensed to Holy Cross College. The research project was authorized by the Bioethics Committee at Holy Cross College in Kielce, resolution 1/10/KB dated 29.01.2010.

\section{Results}

A significant decrease of VAS $(p=0.000)$ was seen in the shockwave group (group 1) just after the end of ESWT and in the period after the end of ESWT 3 months later and in the period from 3 months to 6 months after the end of ESWT at three reference points - at rest, when walking on awakening, and after normal daily activity. No significant decrease of VAS was seen in the control group (group 2) just after the end of CT at rest $(p=0.202)$, when walking on awakening $(p=0.367)$ and after normal daily activity $(p=0.341)$. No significant decrease of VAS was seen in the period after the end of CT 3 months later at rest $(p=0.367)$, when walking on awakening $(p=0.630)$ and after normal daily activity $(p=0.633)$. Also, no significant decrease of VAS was seen in the period from 3 months to 6 months after the end of $C T$ at rest $(p=0.608)$, when walking on awakening $(p=0.337)$ and after normal daily activity $(p=0.393)$. Studies have shown that ESWT reduces pain more effectively than CT in males with chronic HS (Table 1).

The analgesic efficacy of ESWT is confirmed by the detailed analysis of differences in the frequency of occurrence of pain intensity between groups. In the shockwave group (group 1) excellent improvement (a VAS reduction of over $50 \%$ ) was seen in 22/30 (73.3\%) patients, good improvement (a VAS reduction of over $30 \%$ to $50 \%$ ) was seen in $6 / 30(20 \%)$ patients and slight improvement (a VAS 
Table 1. The intensity of pain (VAS) in the following terms of research at three reference points

\begin{tabular}{|c|c|c|c|c|c|c|c|c|c|}
\hline \multicolumn{10}{|c|}{ Shockwaves group (group 1) } \\
\hline $\begin{array}{c}\text { Three Reference } \\
\text { Point }\end{array}$ & \multicolumn{3}{|c|}{ when at rest } & \multicolumn{3}{|c|}{ when walking on awakening } & \multicolumn{3}{|c|}{ after normal daily activity } \\
\hline Variables & $\Delta \mathrm{x} \pm \mathrm{SD}$ & F-Value & P-Value & $\Delta \mathrm{x} \pm \mathrm{SD}$ & F-Value & P-Value & $\Delta \mathrm{x} \pm \mathrm{SD}$ & F-Value & P-Value \\
\hline $\begin{array}{l}\text { VAS } \\
\text { Before the ESWT } \\
\text { VAS } \\
\text { After the last } \\
\text { session ESWT }\end{array}$ & $\begin{array}{l}7.4 \pm 0.9 \\
5.8 \pm 0.7\end{array}$ & $59.077^{*}$ & 0.000 & $\begin{array}{l}8.3 \pm 0.9 \\
6.1 \pm 0.8\end{array}$ & $100.138^{*}$ & 0.000 & $\begin{array}{l}8.5 \pm 0.9 \\
6.2 \pm 0.7\end{array}$ & $122.077^{*}$ & 0.000 \\
\hline $\begin{array}{l}\text { VAS } \\
\text { After the last } \\
\text { session ESWT } \\
\text { VAS } \\
3 \text { months } \\
\text { after ESWT }\end{array}$ & $\begin{array}{l}5.8 \pm 0.7 \\
3.9 \pm 0.8\end{array}$ & $95.841^{*}$ & 0.000 & $\begin{array}{l}6.1 \pm 0.8 \\
4.4 \pm 0.6\end{array}$ & $86.700^{*}$ & 0.000 & $\begin{array}{l}6.2 \pm 0.7 \\
4.6 \pm 0.7\end{array}$ & $78.367^{*}$ & 0.000 \\
\hline $\begin{array}{l}\text { VAS } \\
3 \text { months } \\
\text { after ESWT } \\
\text { VAS } \\
6 \text { months } \\
\text { after ESWT }\end{array}$ & $\begin{array}{l}3.9 \pm 0.8 \\
2.5 \pm 0.7\end{array}$ & $52.035^{*}$ & 0.000 & $\begin{array}{l}4.4 \pm 0.6 \\
3.0 \pm 0.7\end{array}$ & $69.176^{*}$ & 0.000 & $\begin{array}{l}4.6 \pm 0.7 \\
3.5 \pm 0.6\end{array}$ & $42.706^{\star}$ & 0.000 \\
\hline \multicolumn{10}{|c|}{ Control group (group 2) } \\
\hline $\begin{array}{l}\text { VAS } \\
\text { Before } \\
\text { conservative } \\
\text { treatment } \\
\text { VAS } \\
\text { After the last } \\
\text { conservative } \\
\text { treatment }\end{array}$ & $8.1 \pm 0.9$ & 1.667 & 0.202 & $\begin{array}{l}8.6 \pm 0.9 \\
8.4 \pm 0.8\end{array}$ & 0.828 & 0.367 & $\begin{array}{l}8.7 \pm 0.9 \\
8.5 \pm 0.7\end{array}$ & 0.923 & 0.341 \\
\hline $\begin{array}{l}\text { VAS } \\
\text { After the last } \\
\text { conservative } \\
\text { treatment } \\
\text { VAS } \\
3 \text { months after } \\
\text { conservative } \\
\text { treatment }\end{array}$ & $\begin{array}{l}8.1 \pm 0.9 \\
8.3 \pm 0.8\end{array}$ & 0.828 & 0.367 & $\begin{array}{l}8.4 \pm 0.8 \\
8.5 \pm 0.8\end{array}$ & 0.234 & 0.630 & $\begin{array}{l}8.5 \pm 0.7 \\
8.6 \pm 0.9\end{array}$ & 0.231 & 0.633 \\
\hline $\begin{array}{l}\text { VAS } \\
3 \text { months after } \\
\text { conservative } \\
\text { treatment } \\
\text { VAS } \\
6 \text { months after } \\
\text { conservative } \\
\text { treatment }\end{array}$ & $8.4 \pm 0.7$ & 0.265 & 0.608 & $8.7 \pm 0.8$ & 0.937 & 0.337 & $8.8 \pm 0.9$ & 0.741 & 0.393 \\
\hline
\end{tabular}

reduction of over $15 \%$ to $30 \%$ ) was seen $2 / 30$ $(6,7 \%)$ patients at three reference points - at rest, when walking on awakening, and after normal daily activity. There was no decreasing in pain intensity in the control group (group 2), as it was unchanged in 24/30 (80\%) patients and worsened in 6/30 (20\%) patients at these points (Table 2 ).

\section{Discussion}

$\mathrm{HS}$ is a condition that affects more and more people of all ages. It affects their quality of life, reduces socio-professional activity and becomes the cause of frequent sickness absence. The effectiveness of treatment for HS causes many controversial opinions. There is no consensus on how 
Table 2. The analgesic effects of ESWT

\begin{tabular}{|l|c|c|c|c|}
\hline \multirow{2}{*}{} & \multicolumn{2}{|c|}{ Group 1 (shockwave group) } & \multicolumn{2}{c|}{ Group 2 (control group) } \\
\cline { 2 - 5 } & $\mathrm{N}$ & percent & $\mathrm{N}$ & percent \\
\hline VAS $>50 \%$ Reducing & 22 & $73.3 \%$ & - & - \\
\hline VAS $>30-50 \%$ Reducing & 6 & $20 \%$ & - & - \\
\hline VAS>15-30 \% Reducing & 2 & $6.7 \%$ & - & - \\
\hline VAS unchanged & - & - & 24 & $80 \%$ \\
\hline VAS worsened & - & - & 6 & $20 \%$ \\
\hline
\end{tabular}

to treat it, conservatively or surgically. Endoscopy is used most often in surgical treatment. This method is cost-effective, non-invasive, with low risk of postsurgery complications and allows patients to return to socio-professional activity after surgical treatment earlier [8, 19-22]. An alternative to surgical treatment is to use ESWT for treatment of chronic heel spur. There are different opinions on this subject, but the prevalent among them are views highlighting the analgesic efficacy of ESWT in the treatment of chronic HS. The analgesic success of ESWT probably depends on the total dose of energy, not on the density of stream of emitted energy $[18,23-$ 25]. Review of subject literature shows that the analgesic efficacy of ESWT with different physical characteristics and over a different period of time concerning was investigated. Hammer, Adam, Kreutz, Kohn, Seil [14] assessed the analgesic efficacy of ESWT in patients with painful chronic inflammation of the plantar fascia. Patients treated with ESWT were given 3000 impulses of shocks with energy density of $0.2 \mathrm{~mJ} / \mathrm{mm}^{2}$ at weekly intervals. Two years after the end of treatment the level of pain on a VAS scale in patients treated with ESWT decreased $94 \%$. In subsequent studies, the previously mentioned authors used medical ultrasonography to assess the effects of ESWT on changes in thickness of plantar fascia that had been affected by chronic inflammation. During the treatment, 3 sessions of 3000 shock wave impulses with the stream density of $0.2 \mathrm{~mJ} / \mathrm{mm}^{2}$ were applied at weekly intervals. The thickness of plantar fascia was measured $2 \mathrm{~cm}$ distally to calcaneal tuberosity. In addition, the level of pain was recorded in the VAS scale. The ultrasound scan 6 months after the end of ESWT showed a significant reduction in the thickness of plantar fascia of the affected foot and the level of patients pain was reduced $79 \%$ in the VAS scale [26]. Metzner, Dohnalek, Aigner [18] also used ESWT in patients with chronic plantar fascia. Each patient received 1000 impulses of shock wave, the density of energy stream was $0.35 \mathrm{~mJ} / \mathrm{mm}^{2}$. The patients were examined 6 weeks, 16 months and 72 months after the end of ESWT. It turned out that pain was reduced in $81 \%$ of patients after 6 weeks, in $88 \%$ of patients - after 16 months, and in $96 \%$ of patients in the last examination - 72 months after the end of ESWT. Based on these results, the authors concluded that the applied doses of ESWT effectively reduced pain and the achieved therapeutic effects provide satisfactory long-term results. Yalin, Keskin Akca, Selcuk, Kurtaran, Akyuz [27] used ESWT for analgesic purposes in patients with HS and treated them for 5 weeks with 2000 impulses of shock waves, ranging from 0.05 to $0.4 \mathrm{~mJ} / \mathrm{mm}^{2}$. Clinical results demonstrated excellent results (no pain) in $66.7 \%$ of the cases, good results ( $50 \%$ of pain reduced) in $15.7 \%$ of the cases, and unsatisfactory outcome (no reduction in pain) in 17.6 $\%$ of all cases. At the same time, the study showed no correlation between the reduction of pain and a significant modification of the HS in X-ray picture. Moretti, Garofalo, Patella, Sisti, Corrado, Mouhsine [28] evaluated the analgesic efficacy of low doses of ESWT for foot plantar fascia inflammation accompanying HS in runners - athletes. The subjects received a weekly shock wave of 1000 impulses, $0.06 \mathrm{~mJ} / \mathrm{mm}^{2}$ energy density. ESWT continued for four weeks. The patients were examined after the last session of ESWT. Clinical results were excellent in $59 \%$ of cases, good in $12 \%$ of cases, satisfactory in $21 \%$ and clearly unsatisfactory in $8 \%$. Ultrasound examination after the end of ESWT showed the disappearance of inflammatory symptoms in $61 \%$ of athletes.

Cosentino, Falsetti, Manca, De Stefano, Frati, Frediani et al. [29] evaluated the analgesic efficacy ESWT at patients with calcaneal enthesophytosis. Patients were randomly assigned into two equal groups. The shockwave group (group 1) received six treatments (one every 7-10 days), each treatment consisting of 1200 shocks with a frequency of 120 shocks/min; the energy density used varied from 0.03 to $0.4 \mathrm{~mJ} / \mathrm{mm}^{2}$ and the control group (group 2) went through the identical process but energy density was simulated $\left(0 \mathrm{~mJ} / \mathrm{mm}^{2}\right)$. The results revealed significant reduction of pain in the shockwave group (group 1). In the control group (group 2) no significant decrease of VAS was seen.

Wang, Wang, Yang, Weng, Ko [30] evaluated patients with an established diagnosis of chronic plantar fasciitis, including patients in the shockwave treatment group and patients in the control group. In the shockwave group, patients received 1500 
impulses of shockwaves at $16 \mathrm{kV}$ to the affected heel in a single session. Patients in the control group received CT consisting of orthotics, physical therapy, an exercise program, and/or a local cortisone injection. Before treatment, groups showed no significant differences in the scores for pain. After treatment, the shockwave group showed significantly better pain scores in comparison with the control group. The overall results were $69.1 \%$ excellent, $13.6 \%$ good, $6.2 \%$ fair, and $11.1 \%$ poor for the shockwave group and $0 \%$ excellent, $55 \%$ good, $36 \%$ fair, and $9 \%$ poor for the control group.

Our study confirmed the results of other authors. The doses used in ESWT gradually decreased pain intensity in the shockwave group (group 1) and this trend persisted up to 6 months from the last session of ESWT. The observed differences in this period were statistically significant. In the control group (group 2) no significant decrease of VAS was seen after the treatment and in the period from 3 months to 6 months after the end of CT and in the period from 3 months to 6 months after the end of CT in patients with HS. Furthermore, statistically significant differences in pain were also found between the

\section{References}

1. Agostinelly J, Ross JA. Infracalcaneal heel pain in the athlete. Clin Podiatr Med Surg 1997; 14: 503-509.

2. Aquino W, Payne $C$. Function of the plantar fascia. Foot 1999; 9: 73-78.

3. Kim W, Voloshin AS. Role of plantar fascia in the load besring capacity of the human foot. J Biomech 1995; 28: 1025-1033.

4. Puttaswamaiah R. Massive calcaneal enthesopathy in non-healing leg ulcer: a case report. J Orthop Surg 2005; 13: 211-213.

5. Tu P, Bytomski JR. Diagnosis of heel pain. Am Fam Phys 2011; 84: 909-916.

6. Blanco CE, Leon HO, Guthrie TB. Endoscopic treatment of calcaneal spur syndrome:A comprehensive technique. Arthroscopy 2001; 17: 517-522.

7. Jarde O, Diebold P, Havet E, Boulu G, Vernois J. Degenerative lesions of the plantar fascia: surgical treatment by fasciectomy and excision of the heel spur. A report on 38 cases. Acta Orthop Belg 2003; 69: 267-274.

8. Jerosch J, Schunck J, Sokkar SH. Endoscopic calcaneoplasty (ECP) as a surgical treatment of Haglund's syndrome. Knee Surg Sports Traumatol Arthrosc 2007; 15: 927-934.

9. Leitze Z, Sella EJ, Aversa JM. Endoscopic decompresion of the retrocalcaneal space. J Bone Joint Surg Am 2003; 85-A: 1488-1496.

10. Malerba F, De Marchi F. Calcaneal osteotomies. Foot Ankle Clin 2005; 10: 523-540. two groups. Excellent improvement of pain intensity was seen in $73.3 \%$ patients, good improvement was seen in $20 \%$ patients and slight improvement was seen in $6.7 \%$ patients in the shockwave group (group 1) at three reference points: at rest, when walking on awakening, and after normal daily activity. As for the control group (group 1), there was no reduction of pain intensity; it remained unchanged in $80 \%$ of patients and worsened in $20 \%$ of patients at these points. Summing up, the results of shortterm studies show that ESWT effectively reduces pain, which, in turn, reduces mental and physical discomfort in patients with chronic HS.

\section{Conclusion}

The short-term studies have demonstrated the analgesic effectiveness of ESWT. We achieved a significant reduction of pain, that persisted for 6 months in shockwaves group. ESWT reduces pain more effectively than CT in males with chronic HS. The studies have shown that ESWT is a repeatable and non-invasive treatment, and, therefore, is a valuable alternative therapeutic option for surgical treatment and other CT in patients suffering from pain due to chronic HS.

11. Smith WK, Noriega JA, Smith WK Jr. Resection of plantar calcaneal spur using the holmium: yttriumaluminum-garnet (Ho: YAG) laser. J Am Podiatr Med Assoc 2001; 91: 142-146.

12. Stropek S, Dvorak M. Arthroscopic treatment for calcaneal spur syndrome. Acta Chir Orthop Traumatol Cech 2008; 75: 363-368.

13. Chuckpaiwong B, Berkson EM, Theodore GH. Extracorporeal shock wave for chronic proximal plantar fasciitis: 225 patients with results and outcome predictors. J Foot Ankle Surg 2009; 48: 148-155.

14. Hammar DS, Adam F, Kreutz A, Kohn D, Seil R. Extracorporeal shock wave therapy (ESWT) in patients with chronic proximal plantar fasciitis: a 2-year follow-up. Foot Ankle Int 2003; 24: 823-828.

15. Lukowicz M, Weber-Rajek M, Ciechanowska K, Wlodarkiewicz A. The evaluation of the efficacy of low level laser therapy and phonophoresis in calcanean spur symptoms treatment. Acta Bio-Optica Info Med 2009; 15 : 339-343.

16. Robertson V, Baker K. A review of therapeutic ultrasound: effectiveness studies. Phys Ther 2001; 81: 1339-1350.

17. Marks W, Lasek J, Jackiewicz A, LisieskaTyszko S, Gwozdziewicz J, Stasiak M. Treatment of chronic inflammatory soft tissue around the bone structures using extracorporeal source, low-energy shock waves of a new generation - a prospective study. Orthop Quarter 2005; 3: 216-221. 
18. Metzner G, Dohnalek C, Aigner E. High-energy Extracorporeal Shock-Wave Therapy (ESWT) for the treatment of chronic plantar fasciitis. Foot Ankle Int 2010; 31: 790-796.

19. Komatsu F, Takao M, Innami K, Miyamoto W, Matsushita T. Endoscopic surgery for plantar fasciitis: application of a deep-fascial approach. Arthroscopy 2011; 27: 1105-1109.

20. Marks W, Lasek J, Jackiewicz A, Witkowski Z, Stasiak M, Dawid S. Extracorporeal source of low-energy shock waves in the treatment of a new generation of heel spurs - a randomized double blind trial. Orthop Quarter 2008; 2: 219-226.

21. Morafko C. Endoscopic partial fasciotomy as a treatment alternative in plantar fasciitis. Acta Chir Orthop Traumatol Cech 2007; 74: 406-409.

22. Othman AM, Ragab EM. Endoscopic plantar fasciotomy versus extracorporeal shock wave therapy for treatment of chronic plantar fasciitis. Arch Orthop Trauma Surg 2010; 130: 1343-1347.

23. Gerdesmeyer L, Maier M, Haake M, Schmitz C. Physical and technical principles of shock wave therapy. Orthopade 2002; 31: 610-617.

24. Gollwitzer H, Diehl P, von Korff A, Rahlfs VW, Gerdesmeyer L. Extracorporeal shock wave therapy for chronic painful heel syndrome: a prospective, double blind, randomized trial assessing the efficacy of a new electromagnetic shock wave device. J Foot Ankle Surg 2007; 46: 348-357.

25. Ogden JA, Alvarez R, Levitt R, Cross GL, Marlow M. Shock wave therapy for chronic proximal plantar fasciitis. Clin Orthop Relat Res 2001; 387: 47-59.

26. Hammar DS, Adam F, Kreutz A, Rupp S, Kohn D, Seil R. Ultrasonographic evaluation at 6-month followup of plantar fasciitis after extracorporeal shock wave therapy. Arch Orthop Trauma Surg 2005; 125: 6-9.

27. Yalin E, Keskin Akca A, Selcuk B, Kurtaran A, Akyuz M. Effects of extracorporal shock wave therapy on symptomatic heel spurs: a correlation between clinical outcome and radiologic changes. Rheumatol Int 2012; 32: 343-347.

28. Moretti B, Garofalo R, Patella V, Sisti GL, Corrado $M$, Mouhsine E. Extracorporeal shock wave therapy in runners with a symptomatic heel spur. Knee Surg Sports Traumatol Arthros 2006; 14: 1029-32.

29. Cosentino R, Falsetti P, Manca S, De Stefano R, Frati E, Frediani B et al. Efficacy of extracorporeal shock wave treatment in calcaneal enthesophytosis. Ann Rheum Dis 2001; 60: 1064-1067.

30. Wang CJ, Wang FS, Yang KD, Weng LH, Ko JY. Long-term Results of Extracorporeal Shockwave Treatment for Plantar Fasciitis. Am J Sports Med 2006; 34: 592-596. 